\title{
Prediction of the Vase Life of Cut Lily Flowers Using Thermography
}

\author{
Ja Hee Lee, So Young Choi, Hye Min Park, Sang Im Oh, and Ae Kyung Lee* \\ Department of Environmental Horticulture, Dankook University, Cheonan 31116, Korea
}

\begin{abstract}
This study was conducted in order to predict the vase life of cut lily 'Woori Tower' flowers using a non-destructive thermal imaging technique. It was found that the temperature of cut lily flowers was maintained at $20^{\circ} \mathrm{C}$ and was slightly lower than the air temperature until they bloomed. On the 11th day, when flowers bloomed, the temperature of leaves and flowers was measured to be $18.75 \pm 0.38^{\circ} \mathrm{C}$ and $19.23 \pm 0.32^{\circ} \mathrm{C}$ respectively, and their difference with ambient temperature was over $3^{\circ} \mathrm{C}$. The flower temperature increased slightly when the vase life of cut lily flowers ended, and the temperature difference between the air and leaf temperature $\left(1.77^{\circ} \mathrm{C}\right)$ and between the air and flower temperature $\left(1.39^{\circ} \mathrm{C}\right)$ got smaller. No visible aging symptom was observed, but it was found that the temperature had risen due to water losses and less functional stomata. The vase life of cut lily flowers can be predicted based on changes in temperature and it will be also possible to predict the potential quality and vase life of cut flowers before harvesting them in greenhouses.
\end{abstract}

Keywords: infrared camera, Lilium hybrids 'Woori Tower', non-destructive testing, senescence, thermographic image

\section{Introduction}

Cut flowers after being harvested by producers are shipped to wholesale markets to retailers to consumers (An et al., 2018), or are exported to overseas markets through distribution companies in domestic and foreign countries and are distributed to wholesale markets to retailers to consumers (Choi et al., 2018). Recently, a number of studies have been conducted around the world to improve the quality of cut flowers after being harvested, and various attempts have been made to improve the quality of cut flowers after being harvested by developing ways to advance pretreatment and storage, selection and distribution systems, and preservation solutions (Choi et al., 2018). Due to the characteristics of cut flowers, however, cut flowers face issues such as diseases that are not expressed when being harvested, shipping, and contamination in storage environments from harvesting cut flowers to selling them to consumers and these problems reduce the quality and vase life of cut flowers.

The growth of plants so far has been assessed using a method that contacts and destroys plants, and has been repeatedly measured at each growth stage in order to reduce errors. Using an infrared thermal camera, the growth of plants can

This study was supported by the Export Strategy Technology Development Project for "the Establishment of Wet Distribution Systems for Export Promising Cut Flowers (Rose, Chrysanthemum, Lily)" of the Korea Institute of Planning and Evaluation for Technology in Food, Agriculture, and Forestry (IPET) (IPET 316016-04-4-HD040).

Received: March 29, 2019, Revised: May 2, 2019, Accepted: June 13, 2019

First author: Ja Hee Lee, E-mail: 242love@hanmail.net, (1) https://orcid.org/0000-0001-5473-1691

*Comesponding author: Ae Kyung Lee, E-mail: akleekr@dankook.ac.kr, (1) https://orcid.org/0000-0003-2098-0360 
be monitored in a non-destructive and non-contacting method (Kim and Ryu, 1998). This can be utilized in continuously monitoring changes in the physiological conditions of plants grown in greenhouse without damaging them and in controlling the conditions of greenhouses depending on the growth of plants (Kim and Ryu, 1998). Thermal imaging technology measures the amount of radiant energy that each object has depending on infrared wavelengths, and expresses it as temperature, and infrared thermal imaging cameras using the technology express the intensity distribution of infrared light that each object has on thermal images (Kim, 2011; Kim et al., 2001). Recently, many studies on infrared thermography using as a non-destructive and non-contracting method have been conducted in various fields such as construction, power utilities, medicine and aviation and aerospace (Kim, 2011). In the agricultural industry in Korea, the surface temperature of Hedera helix used as a landscape plant was measured using a non-destructive measurement method to identify low-temperature and cold-wind damage (Seong, 2012), and water stress in lettuce, cabbage, cucumber and chili pepper that are grown in greenhouse was analyzed by monitoring plants based on thermographic data (Kim et al., 1999). Changes in plants depending on nutrient stress were also measured (Ryu et al., 2000). Many studies using infrared thermography techniques have already been conducted in other countries, including those on moisture stress in chrysanthemum using a thermal image camera (Blom-Zandstra and Metselar, 2006), moisture stress in grapevine plants (Grant et al., 2006), and downy mildew on roses (Gómez et al., 2012). As such, it is possible to predict and respond to stress on plants before stress symptoms are observed by monitoring plants using a thermal imaging camera. Many studies have been conducted in the agricultural industry at home and abroad to identify the correlation between various stresses and temperature of plants by measuring changes in the temperature of plants and temperature between healthy plants based on thermal images, but there have been only few studies that monitored changes in thermal images by targeting specific plants and analyzing stress. This study aimed to provide basic data to predict and early diagnose the vase life of cut flowers using a thermal imaging camera before the aging of cut lily flowers is visually displayed.

\section{Materials and Methods}

\section{Testing materials}

Woori Tower (Lilium hybrids 'Woori Tower'), cut flowers of Lilium longiflorum, grown in a farm located in Gwacheon, Gyeonggi-do, Korea in November, 2018 were used as testing materials. Flowers were dipped in tap water right after being harvested, and harvested cut flowers were packed dry. Considering the process of shipping and inspecting them via a low-temperature vessel to importing countries, they were stored at $5^{\circ} \mathrm{C}$ in a low-temperature storage for 12 hours, and were exposed to room temperature for 3 hours (Choi et al., 2018). On the 3rd day after being harvested, the time of being sold at auction houses in importing countries, cut lily flowers were cut to lengths of $50 \mathrm{~cm}$, and lower leaves were removed. They were put in a Erlenmeyer flask filled with $500 \mathrm{ml}$ of distilled water.

\section{Surveyed items on experimental environments}

The quality of cut flowers was assessed focusing on their aging conditions and vase life, and the vase life of cut flowers was calculated by counting days until more than one of the aging conditions of plants including wilting, browning and non-flowering was observed. Aging conditions were expressed by converting their frequency into a percentage. In addition, to predict the conditions of cut lily flowers in a non-destructive way, images were taken every two days using a thermal imaging camera (FLIR T-620, FLIR Systems Inc., USA) with the resolution of $640 \times 480$ pixels that can measure the temperature between $-40^{\circ} \mathrm{C}$ and $650^{\circ} \mathrm{C}$, and the distance between cut flowers and the camera was maintained at 
$1 \mathrm{~m}$. Changes in cut lily flowers were observed with the naked eye and a digital camera, and images taken using the thermal image camera were analyzed using QuickReport 1.2 Program (FLIR Systems Inc., USA) to examine changes in temperature until cut flowers reached their vase life. The temperature of cut lily flowers was measured by dividing them into flowers, leaves and ambient temperature (Figure 1), and differences in the temperature between ambient air and leaves, and between ambient air and flowers were calculated based on the measured temperature.

\section{Results and Discussion}

To predict the vase life of cut lily flowers, changes in the temperature of lily were analyzed based on the data collected using a thermal imaging camera and ambient temperature (Figures 2 and 3), and similar temperature changes were observed in flowers and leaves until the vase life of cut lily flowers ended.

Changes in the temperature of cut lily flowers were measured. For the first seven days after treatment, they remained unbloomed, and their temperature was maintained at $20^{\circ} \mathrm{C}$ similar to ambient temperature without any change in their temperature. After 7 days, cut lily flowers started to bloom, and the temperature of flowers and leaves started to decrease, showing a significant difference with ambient temperature. According to the results of thermal imaging experiments on

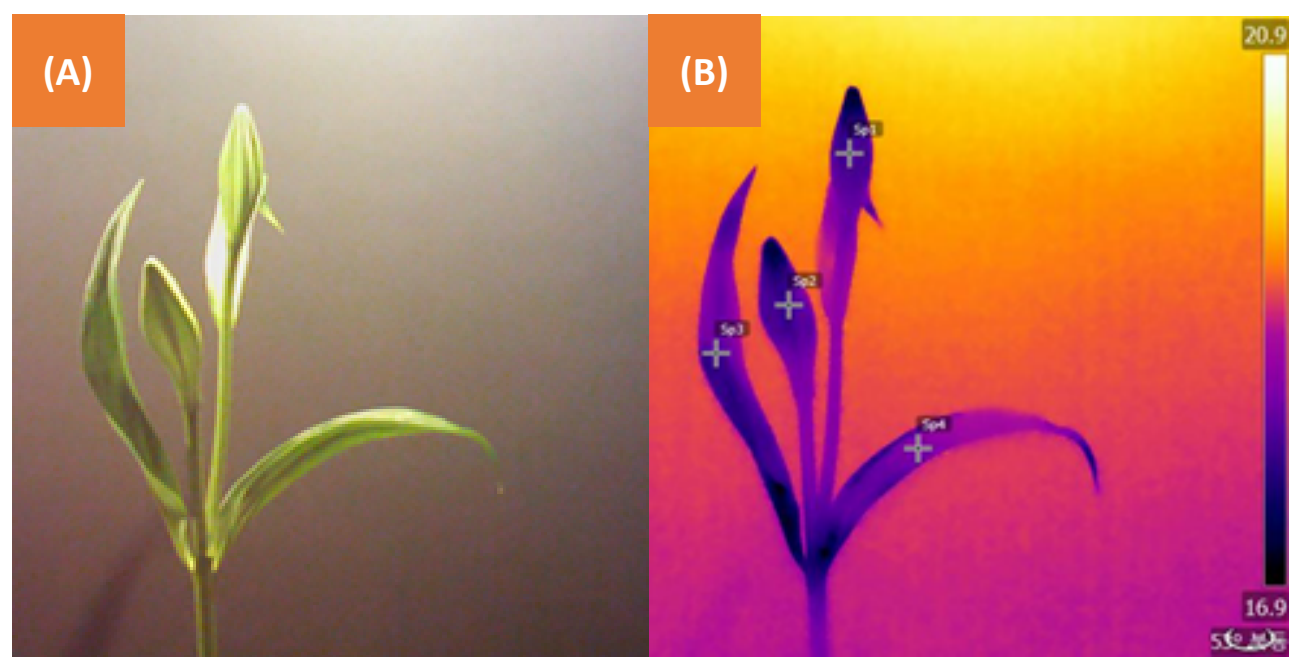

Figure 1. Images of cut lily 'Woori Tower' visualized by a digital camera (A) and a thermographic camera (B).
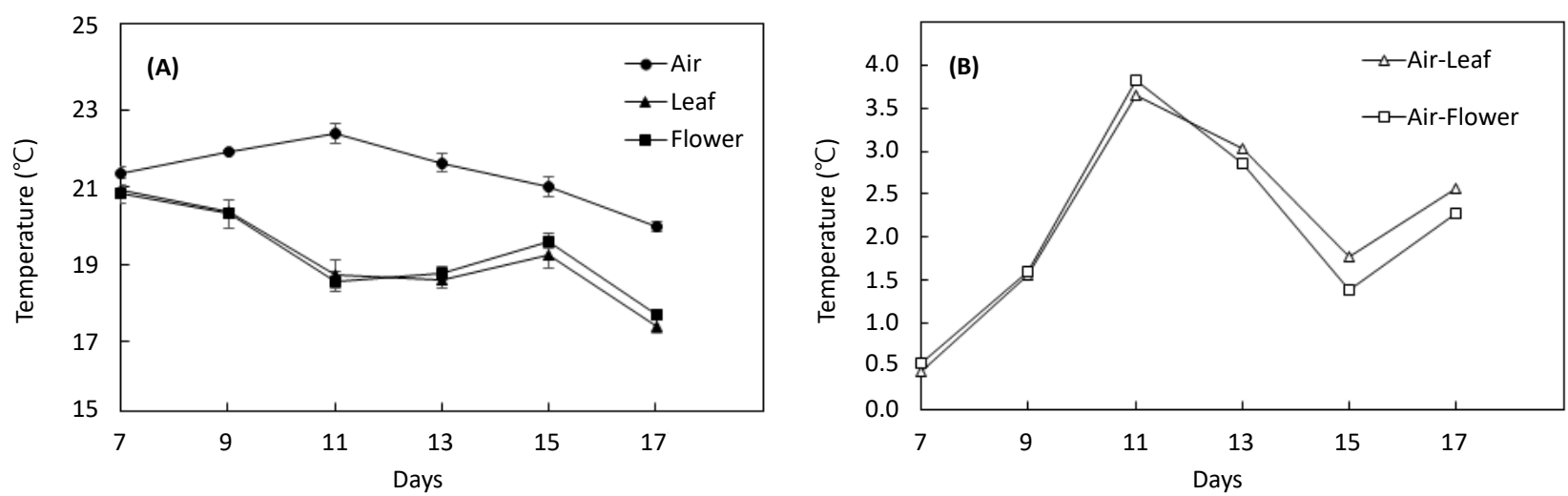

Figure 2. Changes in air temperature, leaf and flower temperature of cut lilies $(A)$ and temperature differences between air and cut lily surfaces (B). Bars represent standard deviation of mean values. 
Lilium hybrids Woori Tower flowers, they fully bloomed right after they started to bloom due to the characteristics of the variety (Park et al., 2019). For this reason, it was difficult to maintain their quality after they fully bloomed, and phenomena such as wilting and browning were observed in this experiment. In particular, on the 11th and 15th days after treatment, the most characteristic change in the temperature of cut lily flowers was observed (Table 1). On the 11th day after treatment when they bloomed, the temperature of flowers and leaves was $18.75 \pm 0.38^{\circ} \mathrm{C}$ and $18.57 \pm 0.25^{\circ} \mathrm{C}$ respectively, and showed a difference of over $3^{\circ} \mathrm{C}\left(3.65^{\circ} \mathrm{C}\right.$ and $3.83^{\circ} \mathrm{C}$ respectively) with ambient temperature. Until right after the vase life of cut lily flowers ended, their temperature continued to increase slightly, and on the 15th day after treatment, the difference between the temperature of flowers and leaves and ambient temperature was reduced to $1.77^{\circ} \mathrm{C}$ and $1.39^{\circ} \mathrm{C}$ respectively. These results show that the temperature of cut lily flowers started to slightly increase from the 11th day after treatment, 3 days before their vase life ended, and from the 13th day the temperature of leaves started to increase. The vase life of Lilium hybrids Woori Tower flowers was found to be 14 days, and that their vase life ended showing phenomena such as wilting, browning and non-flowering (Figure 3).

As flowers significantly wilted, the temperature of cut flowers started to decrease from the 15th day when the vase life of cut flowers ended, and as ambient temperature decreased, the temperature of flowers and leaves was also reduced together. Kim et al. (2014) measured the temperature of pepper seeds that aged and died using a thermal imaging camera and reported that the temperature was slightly lower than normal pepper seeds. As such, the results of this study were similar to those that lower photothermal signals were observed in images taken by a thermal imagining camera. When crops are under stress, the temperature of leaves increases compared to ambient temperature (Idso, 1982; Kim et al., 2015). In this experiment, the temperature of cut lily flowers and leaves was lower than ambient temperature from the first day to the day when their vase life ended, showing changes in the temperature of flowers and leaves. In addition, due to low humidity in the environment of this experiment, vapor pressure deficit (VPD) increased, which resulted in excessive trans-

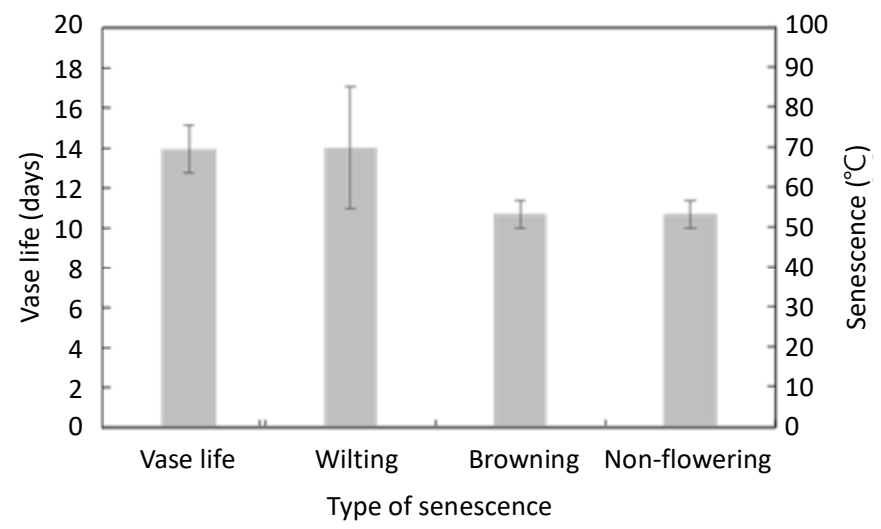

Figure 3. Average vase life and three senescence types observed the end of vase life of cut lily 'Woori Tower.' Bars represent standard deviation of mean values.

Table 1. Comparisons of temperature differences between air and cut lily surfaces at the 11th and 15th day of vase life

\begin{tabular}{lccccc}
\hline \multirow{2}{*}{ Days after harvest } & \multicolumn{5}{c}{ Temperature $\left({ }^{\circ} \mathrm{C}\right)$} \\
\cline { 2 - 6 } & Air (A) & Leaf $(\mathrm{B})$ & Flower $(\mathrm{C})$ & Difference $(\mathrm{A}-\mathrm{B})$ & Difference $(\mathrm{A}-\mathrm{C})$ \\
\hline 11 & $22.40^{\mathrm{z}} \pm 0.26$ & $18.75 \pm 0.38$ & $18.57 \pm 0.25$ & 3.65 & 3.83 \\
15 & $21.00 \pm 0.26$ & $19.23 \pm 0.32$ & $19.61 \pm 0.21$ & 1.77 & 1.39 \\
\hline
\end{tabular}

${ }^{\mathrm{z}}$ Values are mean $\pm \mathrm{SD}$. 
piration and a lower temperature of flowers and leaves than ambient temperature (Lee and Lee, 2001; Nam et al., 2014).

The water balance of cut lily flowers was measured (Figure 4). As cut lily flowers continued to bloom until the 11th day of this experiment, their water balance was measured to have ' + ' values, and after the 11th day, their water balance started to decrease to '-' values. Cut lily flowers seemed to start to age from this moment although any symptom was not observed. Their water absorption amount continued to decrease until the 11th day, while their fresh weight continuously increased. After they bloomed, their water absorption amount was maintained, and their fresh weight showed a downward curve. While their water absorption slightly decreased, their fresh weight gradually increased through their respiration.
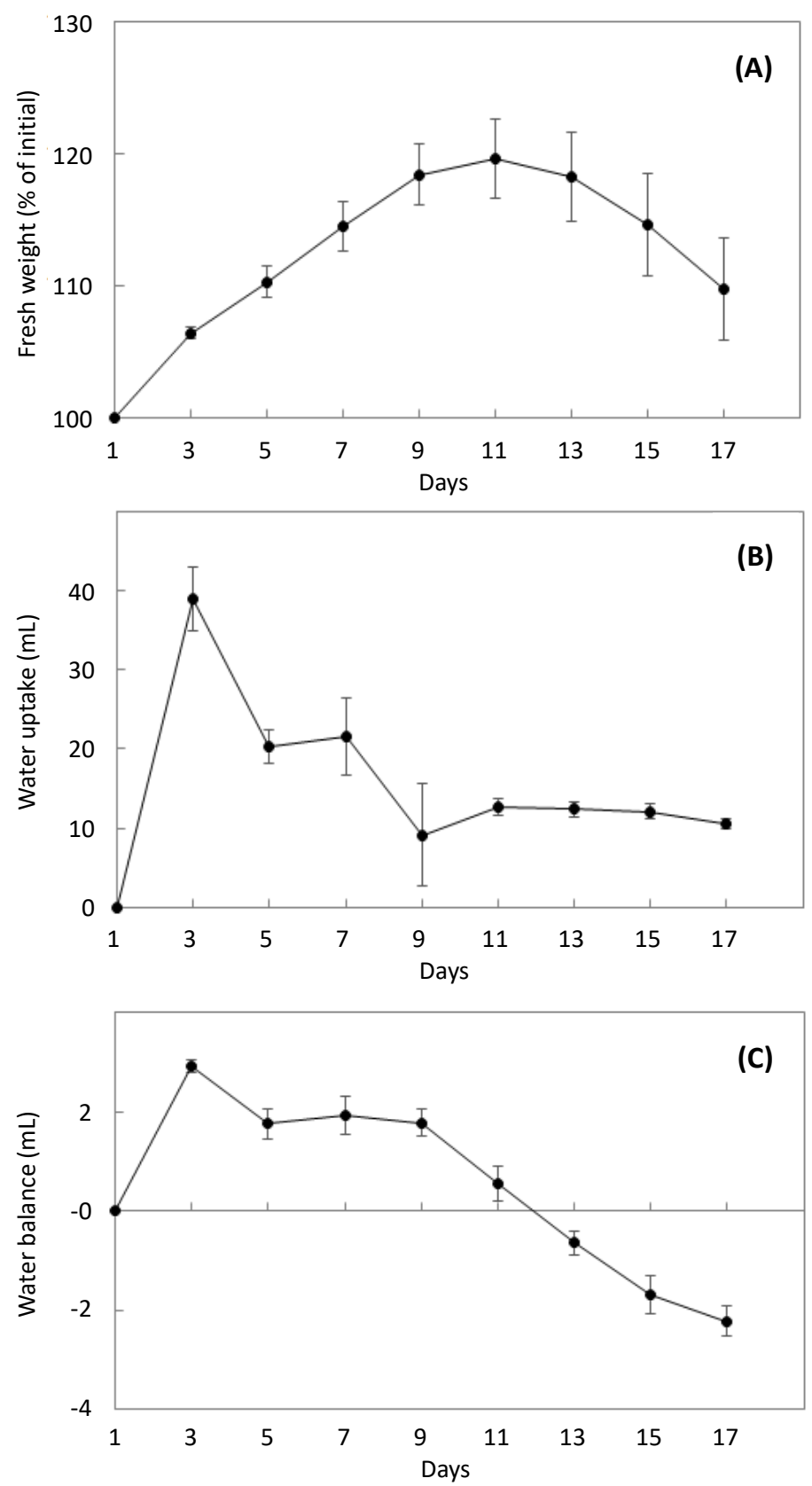

Figure 4. Changes in fresh weight (A), water uptake (B), and water balance (C) of cut lily 'Woori Tower.' Bars represent standard deviation of mean values. 
Several studies were conducted to analyze abnormal symptoms observed in plants using a thermal imaging camera. Hashimoto et al. (1984) analyzed the thermal images of sunflower leaves under water stress, and reported that the temperature of leaves under water stress started to increase from the edge of leaves, about $3 \sim 5^{\circ} \mathrm{C}$ higher than that of normal sunflower leaves, which was attributed to the closed stomata of leaves due to the aging of leaves. Gómez et al. (2012) inoculated downy mildew strains into roses and analyzed their images taken by a thermal imaging camera, and reported that their temperature slightly increased until the 3rd day of inoculation and started to decrease from the 13th day when the disease occurred. Lee et al. (2014) that analyzed the thermal images of cucumbers under water stress reported that their temperature slightly increased, and concluded that stress on plants can be detected in a non-destructive manner using thermal images. Biju et al. (2018) analyzed changes in the temperature of lentils depending on the level of water stress, and reported that the temperature of seeds under a higher water stress was about $2^{\circ} \mathrm{C}$ higher on average, which was similar to the results of this study. Jones and Leinonen (2003) reported that the temperature of leaves is an important indicator on the moisture of plants.

As such, infrared thermography, one of non-destructive biometric recognition technologies, is used to diagnose the stress of plants, and has been used in several studies on the diseases of cut flowers (Gómez et al., 2012; Oerke et al., 2006) or water stress (Hashimoto et al., 1984; Kim et al., 1999; Blom-Zandstra and Metselar, 2006). This study focused on the applicability of infrared thermography to the prediction of the vase life of cut flowers, and additional studies need to be conducted to distribute this facility and predict the potential quality and vase life of lily flowers before harvesting them.

\section{Conclusion}

This study predicted the vase life of Lilium hybrids Woori Tower, a cut flower of Lilium longiflorum, using a thermal imaging camera through infrared thermography, one of non-destructive biometric recognition technologies. As a result, similar changes in the temperature of flowers and leaves were observed until the vase life of cut lily flowers ended. From the 7th day of this experiment, cut lily flowers started to bloom, and the temperature of flowers and leaves started to decrease below ambient temperature, and on the 11th day when flowers fully bloomed the temperature of flowers and leaves slightly increased and showed a difference of over $3.65^{\circ} \mathrm{C}$ and $3.83^{\circ} \mathrm{C}$ respectively with ambient temperature. No abnormal symptom was observed with the naked eye until the 11th day, but the water balance of cut lily flowers decreased to '-' values, which indicates that cut lily flowers started to age from the day. After 4 days, on the 15th day, the aging of cut lily flowers was observed with the naked eye, the difference between the temperature of flowers and leaves and ambient temperature was slightly reduced to $1.77^{\circ} \mathrm{C}$ and $1.39^{\circ} \mathrm{C}$ respectively compared to the day when cut lily flowers bloomed. Cut Woori Tower lily flowers showed a temperature difference of about $3{ }^{\circ} \mathrm{C}$ with ambient temperature both in their leaves and flowers compared to the time of blooming, and the difference between the temperature of leaves and flowers and ambient flowers when cut lily flowers started to age was about $1.4-1.8^{\circ} \mathrm{C}$. These results indicated that it is possible to predict the vase life of cut lily flowers based on changes in the temperature of lily leaves and flowers with naked eyes using a thermal imaging camera before the symptoms of stress are observed. It will be necessary to conduct an additional study on the rate of opened and closed stomata together in order to allow farms to predict the quality and vase life of cut flowers based on the rate before harvesting cut flowers.

\section{References}

An, H.S., J.W. Hong, E.J. Jang, A.K. Lee, and J.Y. Kim. 2018. Current status and recognition of floral preservatives in Korean flower shops. Flower Res. J. 26(4):209-215. 
Biju, S., S. Fuentes, and D. Gupta. 2018. The use of infrared thermal imaging as a non-destructive screening tool for identifying drought-tolerant lentil genotypes. Plant Physiol. Biochem. 127:11-24.

https://doi.org/10.1016/j.plaphy.2018.03.005

Blom-Zandstra, M. and K. Metselar. 2006. Infrared thermometry for early detection of drought stress in chrysanthemum. HortScience 41(1):136-142. https://doi.org/10.21273/HORTSCI.41.1.136

Choi, S.Y., J.H. Lee, and A.K. Lee. 2018. Comparison of pretreatments and shipping solutions for Lilium OT Hybrid 'Zambesi' export. Korean J. Hortic. Sci. Technol. 36(6):876-884. https://doi.org/10.12972/kjhst.20180085

Gómez, S., E.C. Oerke, H.W. Dehne, and U. Steiner. 2012. Thermography as sensor for downy mildew on roses. Proceedings of International Society of Precision Agriculture. Retrieved from https://www.ispag.org

Grant, O.M., L. Tronina, H.G. Jones, and M.M. Chaves. 2006. Exploring thermal imaging variables for the detection of stress responses in grapevine under different irrigation regimes. J. Exp. Bot. 58(4):815-825.

Hashimoto, H., T. Ino, P.J. Kramer, A.W. Naylor, and B.R. Strain. 1984. Dynamic analysis of water stress of sunflower leaves by means of a thermal image processing system. Plant Physiol. 76(1):266-269.

Idso, S.B. 1982. Non-water-stressed baselines: A key to measuring and interpreting plant water stress. Agric. Meteorol. 27(1-2):59-70. https://doi.org/10.1016/0002-1571(82)90020-6

Jones, H.G. and I. Leinonen. 2003. Thermal imaging for the study of plant water relations. J. Agric. Meteorol. 59(3):205217. https://doi.org/10.2480/agrmet.59.205

Kim, D.Y. 2011. A study on diagnosis state monitoring of ball bearing using the infrared thermography method. Master's thesis, Chonbuk National University, Jeonju, Korea.

Kim, G.S., G.H. Kim, S. Lohumi, J.S. Kang, and B.K. Cho. 2014. Viability estimation of pepper seeds using time-resolved photothermal signal characterization. Infrared Phys. Technol. 67:214-221. https://doi.org/10.1016/j.infrared.2014.07.025

Kim, G.Y. and K.H. Ryu. 1998. Crop growth measurements by image processing in greenhouse-for lettuce growth-. J. Korean Soc. Agric. Mach. 23(3):285-290.

Kim, G.Y., K.H. Ryu, and H.Y. Chae. 1999. Analysis water stress of greenhouse crops using infrared thermography. J. Korean Soc. Agric. Mach. 24(5):439-444.

Kim, H.G, D.M. Son, H.N. Kim, K.C. Cho, B.K. Yoon, and J.H. Lee. 2015. Effects of water limit within rhizosphere on the leaf temperature changes of tomato plants. Agric. Sci. Technol. Res. 51:7-10. https://doi.org/10.29335/tals.2015.51.7

Kim, J.Y., S.U. Yoon, N.B. Yim, S. Yu, S.D. Ma, D.J. Yang, and I.S. Song. 2001. Thermo-analysis of machining center main-aixs thermos-displacement for infrared rays thermos-image camera. Proceedings of KSMTE spring conference 2001 (pp. 125-130). The Korean Society of Machine Tool Engineers.

Lee, J.H., M.J. Kang, J.H. Lee, S.M. Park, and A.K. Lee. 2014. Measurement technology of water stress for Cucumis sativus using infrared thermography (Abstr.). Korean J. Hortic. Sci. Technol. 32(Supple. I):221-222.

Lee, N.H, H.S. Lee, 2001. Using leaf temperature for irrigation scheduling in greenhouse. J. Korean Soc. Agric. Eng. 43(6):103-112.

Nam, S.W., Y.S. Kim, and D.U. Seo. 2014. Change in the plant temperature of tomato by fogging and airflow in plastic greenhouse. Protected Hort. Plant Fac. 23(1):11-18. http://dx.doi.org/10.12791/KSBEC.2014.23.1.011

Oerke, E.C., U. Steriner, H.W. Dehne, and M. Lindenthal. 2006. Thermal imaging of cucumber leaves affected by downy mildew and environmental conditions. J. Exp. Bot. 57(9):2121-2132.

Park, H.M., S.I. Oh, S.Y. Choi, J.H. Lee, and A.K. Lee. 2019. Prediction of vase life using infrared thermography on cut lily flowers. Proceedings of Korean Society for Floricultural Science annual spring conference. 27:15.

Ryu, K.H., G.Y. Kim, and H.Y. Chae. 2000. Plant growth monitoring using thermography -analysis of nutrient stress-. J. Korean Soc. Agric. Mach. 25(4):293-300.

Seong, B.K. 2012. An analysis method on injury symptoms utilizing infrared thermal imaging under the freezing stress of Hedera helix L. J. Korean Inst. Landsc. Archit. 40(6):173-179. 